\title{
Radiogenic Stable Isotope Analyses of Fossil Diatoms: Implications of Geochemical Composition for Paleoenvironmental Reconstruction using advanced computational Multi-Taper Method (MTM)
}

\section{AFSOON MOATARI-KAZEROUNI ${ }^{1}$}

${ }^{1}$ Center for susstanability Studies, Geology Department, Bemidji State University

Some of the marine macrofossils isotopic data preserves a signal that suggest early-stage diagenesis, and glacial lake water with $\delta^{180}$ values within previously described similar values. Computer Analysis of Diffraction Data and Multi-Taper Method as a modern technique supports the concept that assessing the diagenetic alteration of macrofossils accurately categorises sediment cores that can be analyzed

diatom fossils and sediment geochemistry to investigate human effects on the lakes over the last centuries. However, the method could be used to evaluate the utility of diatom fossil for palaeoenvironmental interpretation from a wide range of geological settings. The sediment fabric formation and diagenetic processes petrography and isotope results infer that the environment of diagenesis and the oxygen isotope values can provide crucial information for interpreting compositional records and their regional and palaeoclimatic significance. The seasonal deposition model will be used to reconstruct multidecadal time series from each core, which will be subjected to multi-taper method spectral analysis to determine any significant periodicities occurring within the records ${ }^{[1]}$. The seasonal deposition model will be used to reconstruct multidecadal time series from each core, which will be subject to multi-taper method spectral analysis to determine any significant periodicities occurring within the records. Finally, the diatom lamina thickness analysis will be compared to the records of biomarker concentration and investigate the potential utility of this technique to reconstruct past sea ice conditions at ultra-highresolution.

[1] Holocene sea ice-ocean-climate variability from Adélie Land, East Antarctica, Gregory, 2012 